\title{
The Danish Chiropractic Low Back Pain Cohort (ChiCo): Description and Summary of an Available Data Source for Research Collaborations
}

This article was published in the following Dove Press journal: Clinical Epidemiology

\author{
Alice Kongsted (iD) 1,2 \\ Orla Lund Nielsen (iD) \\ Henrik Wulff Christensen \\ Jan Hartvigsen $\mathbb{D}^{1,2}$ \\ Klaus Doktor ${ }^{1,2}$ \\ Peter Kent (iD ${ }^{2,3}$ \\ Tue Secher Jensen (iD) 1,2,4 \\ 'The Nordic Institute of Chiropractic and \\ Clinical Biomechanics, Odense M 5230, \\ Denmark; ${ }^{2}$ Department of Sports Science \\ and Clinical Biomechanics, University of \\ Southern Denmark, Odense, Denmark; \\ ${ }^{3}$ School of Physiotherapy and Exercise \\ Science, Curtin University, Perth, \\ Australia; ${ }^{4}$ Diagnostic Centre, Silkeborg \\ Regional Hospital, Silkeborg, Denmark
}

Correspondence: Alice Kongsted Email akongsted@health.sdu.dk
Background: Back pain is among the most frequent reasons for care seeking globally. Observational clinical cohorts are useful for understanding why people seek care, the content of that care, and factors related to prognosis. This paper describes the Danish Chiropractic low back pain Cohort (ChiCo) and summarizes the primary characteristics of the population to inform the scientific community of the availability of these data as a resource for collaborative research projects.

Methods: Adults seeking chiropractic care for a new episode of non-specific back pain were enrolled at the initial visit and followed up after 2, 13, and 52 weeks, with a subpopulation having weekly follow-ups for 1 year. Patient-reported and clinical-reported data were collected in an electronic database using the REDCap software (REDCap Consortium, projectredcap.org). Variables were chosen to measure pre-defined research domains and questions and to capture information across health constructs deemed relevant for additional research. Non-responders at 13 and 52 weeks were contacted by phone to maximize followup data and explore differences on core outcomes between responders and non-responders. Results: A total of 2848 patients (mean age 45 years, $59 \%$ men) were included from 10 clinics with $71 \%, 68 \%$ and $64 \%$ responding to follow-ups at 2,13 and 52 weeks, respectively. Most participants (82\%) were employed, nearly half reported current LBP for 1-7 days, and $83 \%$ had experienced LBP episodes previously. We did not identify indications of serious attrition bias. Conclusion: We have described the aims and procedures for establishing the ChiCo cohort, characteristics of the cohort, and available information about attrition bias. These data have the potential to be linked, at an individual participant level, to the extensive Danish population-based registries that measure diverse health and social characteristics.

Keywords: chiropractic, cohort studies, low back pain, primary care

\section{Background}

Low back pain (LBP) affects people of all ages. It is burdensome for individuals and societies and is now the leading cause in the world of years lived with disability for both males and females. ${ }^{1,2}$ For example, half of adults in Denmark report back pain within the previous 2 weeks, $20 \%$ of all sick days in Denmark (5.8 million people) are due to LBP, and the annual cost of LBP in Denmark alone is at least 900 million Euro. ${ }^{3}$

Collectively, guidelines from around the globe endorse the use of nonpharmacological and non-surgical interventions such as advice to remain active and at work, exercise, and manual therapy as front line care for people with LBP. ${ }^{4}$ 
However, more knowledge about who seeks care for their LBP, what happens during the clinical consultation, what treatments are given, how the presence of other cooccurring health conditions influence prognosis, and how expectations and preconceived ideas about LBP affect prognosis and the clinical course is needed before these recommendations can be effectively implemented. Also, an apparent mismatch between clinical guidelines discouraging routine imaging for LBP and the use of imaging asks for knowledge about decisions and consequences related to diagnostic imaging. Large observational studies based on data collected at the point of care are well suited to answer these important clinical questions and have therefore been recommended to study spine pain conditions. $^{5}$

In Denmark chiropractors are primary contact healthcare providers within the universal healthcare system and most people who seek chiropractic care do so because of LBP. ${ }^{6}$ Previous research indicates that as many as $30 \%$ of people seeking care for LBP choose to see a chiropractor as their first contact to the health-care system. ${ }^{7}$ Danish chiropractic practice therefore provides a good setting for studying LBP in primary care, and Danish chiropractors and their patients have been willing to participate in research. For example, a previous cohort study of people seeking care for LBP from Danish chiropractors provided important knowledge about the clinical course of LBP in chiropractic care, ${ }^{8}$ as well as determined to what extent this course can be best predicted by chiropractors by standardised screening tools or by patient expectations of recovery. ${ }^{9-11}$ Furthermore, results from that cohort identified ways for chiropractors to easily screen for psychological factors influential on the prognosis of patients with LBP, ${ }^{12}$ explored which factors were important for patients that consider themselves to be recovered, ${ }^{13}$ and also helped identify which parts of the clinical examination best predicted outcomes of treatment. ${ }^{14,15}$

Many new research questions have emerged since the collection of that first cohort in $2010-2012$, and we therefore designed a new and larger cohort sample of people seeking care for LBP from Danish chiropractors. The aim of this paper is to present that new cohort - the Danish Chiropractic low back pain Cohort (ChiCo) - and describe the data collection procedures, summarize baseline characteristics of that sample, and inform the scientific community of the availability of these data as a resource for collaborative research projects.

\section{Methods}

\section{Design and Feasibility}

ChiCo is a longitudinal observational cohort consisting of adults seeking care for LBP at 10 chiropractic clinics in Denmark. Patient enrolment occurred between 1 November 2016 and 21 December 2018. Baseline data include information from patient-reported information collected prior to seeing the chiropractor (Baseline 1), clinical data entered by the clinician during or shortly after the baseline examination (Clinician Questionnaire), and further patient-reported data after the first consultation with the chiropractor (Baseline 2). Follow-up data were collected two weeks after inclusion (Follow-up 2 weeks), and 3 and 12 months after inclusion (Follow-up 3 months and Follow-up 12 months). A subpopulation received and answered SMS (text) messages weekly for the duration of one year starting on the seventh day after inclusion.

A feasibility test of study logistics, including clinician and patient inclusion, attrition rates, electronic questionnaire procedures, and weekly SMS tracking, was conducted and evaluated in four chiropractic clinics prior to the start of the main study.

Three studies were published based on parts of the cohort before data collection was finished. ${ }^{16,17}$

\section{Setting}

Chiropractic clinics were a convenience sample invited from the Central Administrative Region of Denmark that covers approximately 1.3 million inhabitants (2018). Clinics were identified from personal knowledge about clinics in the area. It was a requirement for participation that the clinics had digital $\mathrm{x}$-ray systems using the national KirPACS (picture archiving and communication system), because that would serve as a single point of access to all images. Only medium or large size clinics were invited to ensure adequate recruitment of study participants within a reasonable timeframe.

Chiropractors in Denmark are self-employed, and almost all clinics (94\%) operate under the agreement between the Danish Chiropractor's Association and the Danish Regions where for most services around $20 \%$ is paid by the region and $80 \%$ by the patient directly or by a private insurance. Reimbursement for chiropractic services is independent of referral from GPs, so many patients self-refer. Approximately $25 \%$ of chiropractic clinics have at least one physiotherapist as part of the clinical staff and $60 \%$ have exercise facilities; ${ }^{18}$ for clinics recruiting for ChiCo this was $90 \%$ and $60 \%$, respectively. 
Introductory meetings with clinicians and secretaries conveying information about the study's aims, research areas and logistics were held at the first four clinics prior to commencement of patient inclusion in November 2016. Two clinics were added in May 2017, another two in November 2017, and in March 2018 the last two were included. In addition, written instructions and checklists for procedures and data collection were provided for clinicians and secretaries.

Once a week during the baseline inclusion period the clinics were contacted by a research assistant who would answer questions from the clinics on project-related procedures and clarify issues, such as why clinician questionnaires had not been completed or why duplicate patients were present in the project database. During the patient inclusion phase clinics were contacted monthly to give feedback on the number of included patients and to thank the clinics for participating in the project. Clinics were reimbursed with DKK 225 ( $€$ 30) for each patient included, in order to compensate for the altered workflow and time taken for completion of the clinician-reported questionnaires.

\section{Participants}

People were eligible for participation if they consulted the involved chiropractic clinics with a new episode of LBP with or without leg pain, were aged 18 years or older and able to complete electronic questionnaires in Danish. A new episode was defined as contacting the clinic for a new or recurring LBP problem for which they were not in an ongoing course of treatment or long-term management. People with suspected systemic pathology leading to referral for diagnostic workup and people referred for acute surgical assessment were not eligible.

Assuming 15\% of patients in Danish chiropractic care receive imaging, 5000 participants were the estimated sample size needed as approximately 750 participants with radiographs, MRI- or CT-scans were needed for subprojects about imaging that had the highest demands for numbers included. ${ }^{19}$ Follow-up by SMS questions was planned only for the first 1200 participants to reduce burden on participants and costs.

\section{Data Collection Setup}

Questionnaire data were collected and stored using the online system REDCap (Research Electronic Data Capture) hosted and supported by the Odense Patient data Explorative Network (OPEN). The use of application programming interface (API) connections from REDCap allowed record ID and mobile phone number to be exported to an SMS-Track service that automated weekly distribution of text message questions.

Eligible patients received an iPad upon arrival to the clinic configured such that only direct access to data entry in REDCap was possible. Activation of the software application resulted in REDCap creating a new automatically numbered record. The first screen informed the patient about the project and requested his or her consent to participate and included details about how contact information and sensitive personal data would be managed within the project. Only by providing consent was it possible for the invited patients to enter their name and the individual unique Danish Central Person Registry (CPR) identification number and thereby get access to the Baseline 1 questionnaire. This procedure also ensured that no follow-up questionnaires would be sent unless consent had been given.

Using contact information from Baseline 1, the Baseline 2 questionnaire was sent to the participant's email after a delay of 15 minutes, which allowed them to respond to it after the consultation with the chiropractor in the clinic or from home using smartphone, tablet or PC. Non-responders to Baseline 2 received an electronic reminder after two days. Upon completion of Baseline 1, follow-up questionnaires were automatically scheduled after 14, 91 and 365 days. In case of non-response, an electronic reminder was sent after three days for follow-up 2 weeks, and seven days after for follow-up 3 months and follow-up 12 months. Participants who did not respond to the email reminder were contacted by telephone by a research assistant who checked for valid email address, reinforced the importance of high response rates, and asked for permission to resend the questionnaire.

From 30 November 2017 onwards, these phone contacts also included the asking of questions on a few core outcomes (see section Follow-up interviews below). Replies were registered separately by the research assistant and the participant was still asked to complete the full questionnaire.

Text messages for the SMS-Track subpopulation were sent weekly for 52 weeks in the late afternoon on the same weekday as the inclusion. Participants were contacted by phone if they had not responded to two or more subsequent messages.

\section{Baseline Questionnaires}

Questionnaires were selected to cover the constructs relevant to predefined research areas and match those in 
previous studies. Validated questionnaires were used where possible, within the constraints of needing to limit the total number of questions.

\section{Patient-Reported Questionnaires}

The Baseline 1 questionnaire included items that were likely to be influenced by the initial consultation with the chiropractor. The Baseline 2 questionnaire contained demographic and background information deemed less likely to be clinician influenced, and questions about the patient's experience of the first consultation. The following is a summary of the constructs covered in the questionnaires by domain (for greater detail see Supplementary File 1 (ChiCo Codebook Patient)).

\section{Patient Demographics and Social Factors}

Information on participants included demographics, general health, education, family factors and work situation.

\section{Pain and LBP History}

Information on LBP history included treatment for current or previous low back pain episodes, triggers of onset of LBP, previous imaging, and pain trajectory pattern over the previous 12 months. Pain intensity was rated on numeric rating scales (NRS) for back pain and leg pain separately, ${ }^{20}$ and participants were asked about duration of current episode and number of days with LBP within the past year.

\section{Expectations and Reassurance}

Participants indicated their expectations relating to the consultation by items on expectations for examination, treatment, advice and information about the condition, prognosis and expected course. Recovery expectations were measured by an item on the Örebro Musculoskeletal Pain Screening Questionnaire (OMPQ). ${ }^{21}$ Perceived reassurance was measured by the Consultation-based Reassurance Questionnaire (CRQ). ${ }^{22,23}$

\section{Psychological Domain}

Information collected about psychological factors included the ability to control pain, and feeling depressed or stressed as assessed by the OMPQ. ${ }^{21}$ Fear avoidance of work activities was measured by the Fear-Avoidance Beliefs Questionnaire, work subscale (FABQ-W), ${ }^{24,25}$ and fear of movement by two items from the Tampa Scale for Kinesiophobia (TSK). ${ }^{26}$

\section{Illness Perception}

Perception and beliefs about LBP were assessed by asking about the perceived cause of LBP (cause component of the
Illness Perception Questionnaire (IPQ)), ${ }^{27}$ attitudes towards imaging, ${ }^{28}$ and back beliefs (Back Beliefs Questionnaire (BBQ)). ${ }^{29}$

\section{Physical Function}

Physical function was measured by assessing activity limitation (Roland Morris 23-item Disability Questionnaire $(\mathrm{RMDQ})),{ }^{20,30}$ and self-perceived physical fitness. ${ }^{31}$

\section{Risk Stratification Index}

General risk of persistent disability was assessed by the STarT Back Screening Tool. ${ }^{32}$

\section{Clinician Reported Data}

The clinical examination data included: 1) inspection (eg, Schober's test and posture), 2) global range of motion and segmental palpation for pain and stiffness, ${ }^{33} 3$ ) neurological examination of the lower extremity (straight leg raise, tendon reflexes, muscle strength, sensation), ${ }^{34,35} 4$ ) orthopaedic examination (eg, SI joint pain provocation tests), ${ }^{36}$ and 5) other examinations (eg, percussion, step-off between spinous processes) (See Supplementary File 2, ChiCo Codebook Clinicians). Additional clinician reported information included: Presence of leg pain or symptoms, suspected neurogenic pain, suspected inflammatory back disease or severe pathology, diagnosis resulting from the examination, previous and planned diagnostic imaging (radiograph, MRI or CT), indications for diagnostic imaging, and treatment plan (Supplementary File 2, ChiCo Codebook Clinicians).

\section{Follow-Up Questionnaires}

All follow-up questionnaires repeated the questions on low back and leg pain intensity, ability to control pain, feeling depressed or stressed, sick leave, current use of medication and activity limitation. Additionally, the follow-up at 2 weeks asked about satisfaction with treatment and global perceived effect (GPE). Both follow-ups at 2 weeks and 3 months repeated the STarT Back Screening Tool. ${ }^{37}$ The BBQ and information on other treatments were included in follow-up 3 months and follow-up 12 months. In only the follow-up 12 months questionnaire these additional items were assessed: perceived cause of LBP, attitudes towards imaging, imaging within the past year, pain trajectory pattern over the past year, work ability and selfperceived physical fitness. 


\section{Follow-Up Interviews}

Participants who had not responded to the 3-month or 12month follow-ups were asked over the phone about their response to the survey questions about typical LBP and leg pain intensity within the past week, ability to control pain, current use of medication, days off sick due to back pain within the past 3 months and current sick leave, and treatment by other practitioners.

\section{Text Message Questions}

The weekly SMS data collection consisted of three questions: (1) "How many days have you had back pain (or back-related leg pain) within the last 7 days? (please answer with one number from 0 to 7)"; (2) "How severe was the pain typically on a scale from 0 to 10 ?"; and (3) "How many days were you home last week from work or study because of your back pain? (please answer with one number from 0 to 7 )". ${ }^{8}$ If the first question was answered with a " 0 ", no further questions were sent. During the first six weeks of the data collection, the third question (asking about days home from work or study) was only sent every second week and asked about the previous two weeks.

\section{Data Preparation}

Biological sex, birthdate and age at inclusion were determined from the participants' CPR number and date of inclusion. The response status of questionnaires and date of response relative to inclusion were created from REDCap's timestamps and logging information. Inconsistencies in integer data (values out of the possible range) were recoded as missing. Questions that remained hidden unless triggered by affirmative response to an introductory question were recoded as " $/ \mathrm{No}$ " or ".a" (missing) as appropriate. For example, "No" to any previous treatment meant that previous treatment by all listed health-care providers was also coded as "No".

\section{Imputation and Sum Scores}

Sum scores were calculated from validated questionnaires (RMDQ, BBQ, STarT, CRQ and FABQ) according to their scoring algorithms (Supplementary file 1). To obtain sum scores from incomplete questionnaires (with at least one question answered), missing items on these scales were imputed using chained multiple imputation informed by scores on those five questionnaires plus back pain intensity at baseline, episode duration, age, sex and previous treatment for back pain by a chiropractor. Due to very unequal response distribution on five RMDQ items these were imputed using monotone sequential imputation. Imputed values were restricted to the range of the original response options. To simplify the use of data, we only generated one imputed data set for the standard ChiCo dataset, although one benefit of multiple imputations is analyses performed across multiple datasets. This was judged to not introduce any considerable bias because a maximum of $5 \%$ of responses were imputed for any of the questionnaires.

\section{Follow-Up Interviews}

Missing items on 3- and 12-months follow-up questionnaires, which were obtained by phone interviews with non-responders, were replaced by the responses obtained at the interviews.

\section{SMS-Track Clearing}

SMS answers where the participant provided a nonnumerical response, eg, "two days" instead of 2, were recoded to a single number whenever the equivalent was obvious. Intervals (3-5), multiple numbers $(3,4,6)$ or decimals (3.5) were recoded to the average and rounded (4). Numbers exceeding the logical range, single letters and otherwise unintelligible messages were recoded as missing.

Because the third SMS-question (days home from work or study only) was sent only every second week during the first six weeks of the data collection and related to the previous two-week period, the reported number of days were distributed equally over the two relevant weeks. For example, an answer of 6 in week 4 about days off work during the past 14 days was recoded as 3 in week 3 and 3 in week 4.

\section{Results}

\section{Feasibility Test}

The feasibility testing was conducted with four clinics enrolling a total of 55 patients, who all completed the Baseline 1 questionnaire. Of these, $70 \%$ completed the Baseline 2 questionnaire, $68 \%$ completed the 2 weeks questionnaire, and $83 \%$ responded to the SMS-Track. Based on interviews with secretaries, clinicians and patients, only minor aspects of the procedures and questionnaires were changed, and data from the feasibility testing was kept as part of the cohort. 


\section{Inclusion and Response Rates}

Ten clinics were recruited. We stopped inclusion of patient participants at the end of 2018 with $\mathrm{n}=2848$ participants included (range 19-906 per clinic). That occurred because the actual imaging rate (imaging performed before seeing the chiropractor or at inclusion) was $37 \%$, rather than the expected $15 \%$. During the inclusion period a total of 3165 record IDs were created. Removing of IDs erroneously created by technical problems and exclusion of people not fulfilling inclusion criteria resulted in a cohort of 2848 who completed the Baseline 1 questionnaire (Figure 1). The lowest response rate was at the 12 months follow-up with $64 \%$ responding to the questionnaire or telephone interview (Figure 1). Of the non-responders, $381(13 \%)$ did not answer any of the follow-up questionnaires or telephone questions. In addition, some questionnaire responses had single items missing because answering all items was not compulsory.

A total of 1378 participants were included in the SMS sub-cohort of whom 1000 (73\%) responded to at least half of the SMS questions, $928(67 \%)$ responded to at least 42 of the 52 weekly SMS-questions, and 195 (14\%) responded for only two weeks or less.

Response times varied somewhat for the follow-up points. On average, participants responded to the Baseline 2 and the 2-week follow-up within 2 to 3 days, and the 3 months follow-up within 7 to 11 days, with some responding very late at all follow-up time points (Table 1).

\section{Participant Characteristics}

The cohort of ChiCo participants had a median age of 45years, approximately half had higher education, $82 \%$ were employed and a minority reported any sick leave. The current LBP episode duration was short ( $\leq 1$ week) in almost half of participants, but $83 \%$ had experienced LBP before (Table 2).

\section{Follow-Up Attrition Bias}

We performed three types of drop-out analyses in order to assess attrition bias: 1) comparing patient characteristics at Baseline 1 between responders and non-responders of Baseline 2 and follow-up at 2 weeks (Table 3); 2) comparing patient characteristics at Baseline 1 between responders, interviewed participants and non-responders to the 3 month and 12 month follow-ups (Table 4); and 3) comparing available outcomes at follow-ups between responders, interviewed participants and non-responders to the 3 and 12 month follow-ups (Table 5).

Non-responders were younger than responders and more often males, but these groups were successfully reached by phone interviews (Table 4). No other substantial differences on baseline characteristics were observed between responders and non-responders (Tables 3 and 4). Further, the interviews demonstrated that the mean improvement experienced by non-responders to questionnaires was similar to the improvement in pain experienced by the responders.

\section{Discussion}

To our knowledge, the ChiCo LBP cohort is the largest and most comprehensive cohort of patients with LBP seeking care from chiropractors, and also one of the largest and most comprehensive cohorts of primary care patients with LBP more generally. The participation rates at both short- and long-term follow-up were satisfactory, and our drop-out analyses indicate minimal attrition bias over the one year. A subset of the cohort (N 1378) provided answers to weekly SMS questions with $73 \%$ responding to at least half of the 52 SMS questions. Some participants responded late to follow-up questionnaires. That is not unique to this sample, but available data on the time of responding will allow researchers to determine how this is handled in the specific future research projects using ChiCo cohort data.

The ChiCo cohort was designed to answer research questions within a number of pre-defined domains. These include questions related to profiling of Danish chiropractic patients; beliefs and attitudes of patients and clinicians in relation to LBP and recovery from LBP and the importance of imaging for LBP; the value of imaging in people seeking care from chiropractors for LBP; prevalence, risk and prediction of sick leave among Danish chiropractic patients; implementation of evidence/evidence-based practice among Danish chiropractors; validation of previously identified LBP trajectories and prediction models in primary care patients with LBP; and a validation of the Consultation Reassurance Questionnaire. That validation study has been published on a subset of the cohort. ${ }^{23}$ Follow-up times and variables were carefully chosen in order to ensure that research questions within these prespecified areas of interest could be answered while keeping the burden on participants and clinicians as low as possible. 
Originally appointed ID's: 1 Nov 2016 - 21 Dec 2018

- 3165 Total
Not included in the project: $\mathbf{3 1 7}$

- 66 Technical failure

- 173 Declined consent

- 74 Excluded, non-musculoskeletal cause of pain

- 4 Excluded, age under 18 years

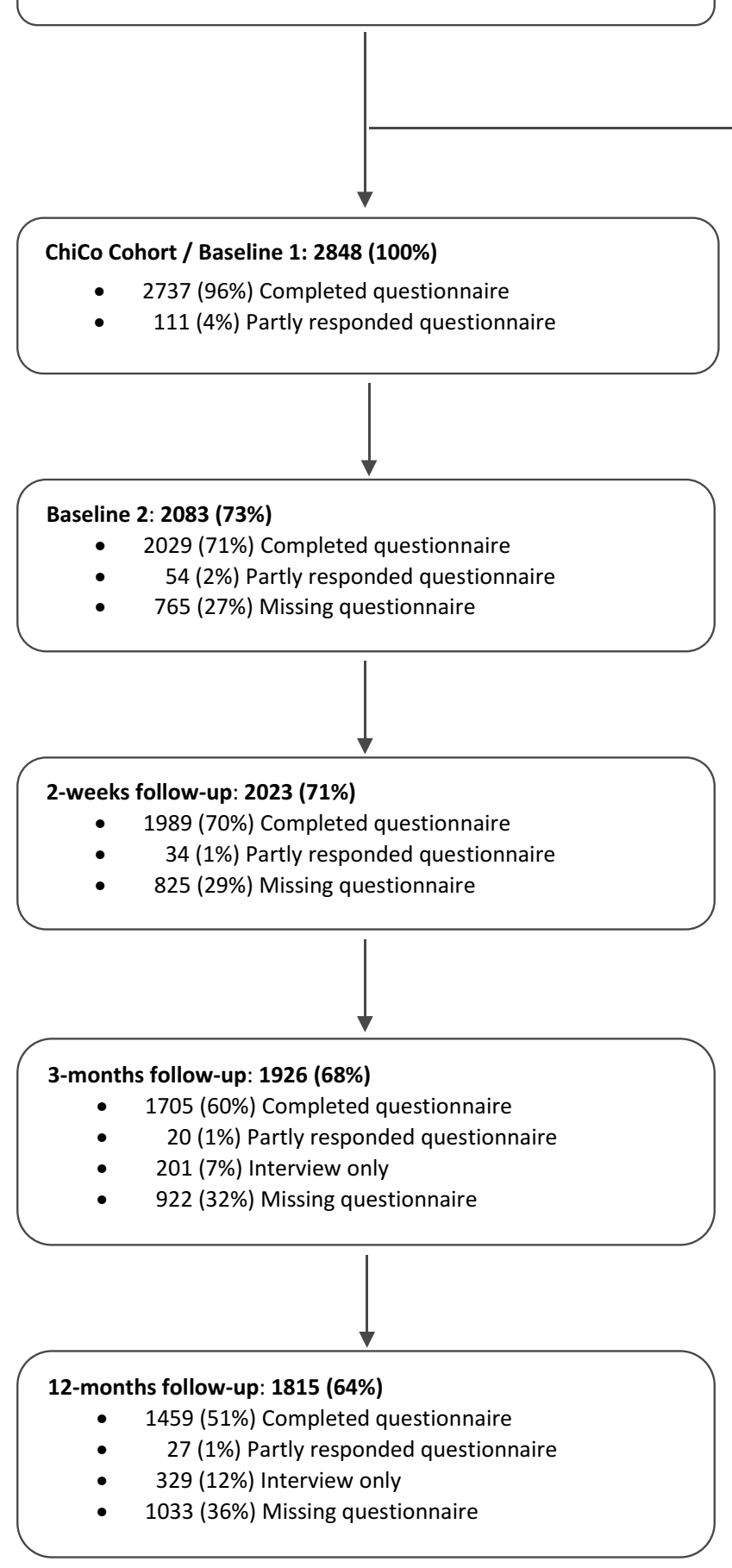

Figure I Flowchart.

Information collected on participants in ChiCo can be merged with information from Danish national registries in order to study outcomes related to broader questions. For example, long-term healthcare consumption in primary care and in hospitals via the Danish National

- 2737 (96\%) Completed questionnaire

- $111(4 \%)$ Partly responded questionnaire

- $2029(71 \%)$ Completed questionnaire

- 54 (2\%) Partly responded questionnaire

765 (27\%) Missing questionnaire

(71\%)

- 34 (1\%) Partly responded questionnaire

- 825 (29\%) Missing questionnaire

- $201(7 \%)$ Interview only

- $922(32 \%)$ Missing questionnaire

- $\quad 329(12 \%)$ Interview only

- $1033(36 \%)$ Missing questionnaire
Health Service register and the Danish National Patient Register, ${ }^{38,39}$ medication prescription from The Danish National Prescription Registry, as well as social outcomes like sick-leave and early retirement via the National Registry on Social transfer Payments (the DREAM 
Table I Response Times for Completed Questionnaires

\begin{tabular}{|c|c|c|c|c|}
\hline Response Times & $\begin{array}{l}\text { Baseline } 2 \\
(\mathrm{~N}=\mathbf{2 0 2 9})\end{array}$ & $\begin{array}{l}2 \text { Weeks } \\
(\mathrm{N}=1989)\end{array}$ & $\begin{array}{l}3 \text { Months } \\
(\mathrm{N}=\mid 705)\end{array}$ & $\begin{array}{l}12 \text { Months } \\
(\mathrm{N}=1459)\end{array}$ \\
\hline Mean (SD); days after distribution & $2.3(3.8)$ & $2.9(5.3)$ & $7.2(10.6)$ & $10.8(20.5)$ \\
\hline Median (IQR); days after distribution & I $(0-3)$ & I (0-4) & $3(0-8)$ & $4(0-9)$ \\
\hline Late response; $\mathrm{n}(\%)^{*}$ & $105(5.2 \%)$ & $219(11.0 \%)$ & $78(4.6 \%)$ & 138 (9.5\%) \\
\hline
\end{tabular}

Notes: *>7 days after distribution for baseline and 2 weeks follow-up; >I month after distribution for 3 and 12 months follow-ups.

Table 2 Participant Characteristics

\begin{tabular}{|c|c|c|c|c|}
\hline Participant Characteristics & Baseline & 2 Weeks & 3 Months & 12 Months \\
\hline Age; mean (SD, full range) & $44.6(13.7 ; 18-87)$ & & & \\
\hline Sex, female; n (\%) & II 67 (4I.0\%) & & & \\
\hline BMI; mean (SD) & $26.9(5.0)$ & & & \\
\hline Smoker, yes; n (\%) & $336(16.2 \%)$ & & & \\
\hline \multicolumn{5}{|l|}{ Longest education: } \\
\hline Higher or further education; $\mathrm{n}$ (\%) & $1040(51.5 \%)$ & & & \\
\hline Vocational education; n (\%) & $594(29.4 \%)$ & & & \\
\hline No qualifying education; $\mathrm{n}(\%)$ & $313(15.5 \%)$ & & & \\
\hline Other education; n (\%) & $74(3.7 \%)$ & & & \\
\hline Employment, yes; n (\%) & $2287(82.2 \%)$ & & & \\
\hline Previous treatment for low back pain, yes; $\mathrm{n}(\%)$ & 1357 (66.4\%) & & & \\
\hline Previous episodes with low back pain, yes; $n$ (\%) & $1652(83.3 \%)$ & & & \\
\hline Days with low back pain within past year, $>30$ days; $n$ (\%) & $752(37.5 \%)$ & & & \\
\hline \multicolumn{5}{|l|}{ Episode duration: } \\
\hline I-7 days; $\mathrm{n}(\%)$ & $1328(47.0 \%)$ & & & \\
\hline I week - 3 months; n (\%) & $1006(35.6 \%)$ & & & \\
\hline$>3$ months; $\mathrm{n}(\%)$ & $494(17.5 \%)$ & & & \\
\hline \multicolumn{5}{|l|}{ STarT Back Tool risk groups } \\
\hline Low; n (\%) & $|2| \mid(42.5 \%)$ & & & \\
\hline Medium; n (\%) & $10 \mid 4(35.6 \%)$ & & & \\
\hline High; n (\%) & $623(21.9 \%)$ & & & \\
\hline $\begin{array}{l}\text { Current use of over the counter and/or prescribed pain killers for back pain, yes; } \\
n(\%)\end{array}$ & $|04|(5 \mid .0 \%)$ & & & \\
\hline Fear-Avoidance, FABQ Work subscale (0-42); mean (SD) & $12.6(9.4)$ & & & \\
\hline Days off sick within past 3 months; median (IQR) & $0(0-1)$ & & & \\
\hline Present sick leave, yes; n (\%) & $74(4.8 \%)$ & $43(2.3 \%)$ & $25(1.3 \%)$ & $20(1.1 \%)$ \\
\hline Back pain intensity, NRS (0-10); mean (SD) & $6.7(2.1)$ & $3.7(2.3)$ & $2.3(2.3)$ & $2.3(2.4)$ \\
\hline Leg pain intensity, NRS (0-10); mean (SD) & $3.0(2.9)$ & $1.9(2.4)$ & $1.3(2.1)$ & I.I (2.0) \\
\hline Back Beliefs, BBQ (9-45); mean (SD) & $32.2(5.9)$ & & $32.8(6.2)$ & $32.0(6.0)$ \\
\hline Activity limitation, RMDQ (0-100); mean (SD) & $55.0(23.8)$ & $30.3(26.1)$ & $19.7(23.5)$ & $20.0(22.8)$ \\
\hline \multicolumn{5}{|l|}{ Clinician reported working diagnosis } \\
\hline Non-specific LBP; n (\%) & $2372(84.7 \%)$ & & & \\
\hline Back related leg pain WITHOUT nerve root involvement; n (\%) & $665(23.8 \%)$ & & & \\
\hline Back related leg pain WITH nerve root involvement; $n$ (\%) & $164(5.9 \%)$ & & & \\
\hline Fracture; n (\%) & $14(0.5 \%)$ & & & \\
\hline $\begin{array}{l}\text { Initial suspicion of systemic pathology (Cancer, Cauda equina syndrome, } \\
\text { Inflammatory rheumatoid arthritis, Infection)*; n (\%) }\end{array}$ & $31(1.1 \%)$ & & & \\
\hline
\end{tabular}

Note: *Participants not excluded because pathology not confirmed. 
Table 3 Characteristics at Baseline I of Responders and Non-Responders to Baseline 2 and 2-Weeks Follow-Up

\begin{tabular}{|c|c|c|c|c|}
\hline \multirow[t]{2}{*}{ Patient Characteristics at Baseline* } & \multicolumn{2}{|l|}{ Baseline 2} & \multicolumn{2}{|l|}{2 Weeks } \\
\hline & $\begin{array}{l}\text { Responders } \\
(\mathrm{N}=\mathbf{2 0 8 3 )}\end{array}$ & $\begin{array}{l}\text { Non-Responders } \\
(\mathrm{N}=765)\end{array}$ & $\begin{array}{l}\text { Responders } \\
(\mathrm{N}=2023)\end{array}$ & $\begin{array}{l}\text { Non-Responders } \\
(\mathrm{N}=\mathbf{8 2 5})\end{array}$ \\
\hline Age; mean (SD) & $46.1(13.5)(n=2083)$ & $40.5(13.4)(n=765)$ & $46.6(13.4)(n=2023)$ & $39.6(13.1)(n=825)$ \\
\hline Sex, female; n (\%) & $918(44.1 \%)(n=2083)$ & $249(32.6 \%)(n=765)$ & $872(43.1 \%)(n=2023)$ & $295(35.8 \%)(n=825)$ \\
\hline Episode duration, $>7$ days; $\mathrm{n}$ (\%) & $1109(53.6 \%)(n=2070)$ & $391(51.6 \%)(n=758)$ & $1078(53.6 \%)(n=2011)$ & $422(51.7 \%)(n=817)$ \\
\hline Back pain intensity, NRS (0-10); mean (SD) & $6.7(2.0)(n=2042)$ & $6.6(2.2)(n=749)$ & $6.7(2.0)(n=1987)$ & $6.7(2.1)(n=804)$ \\
\hline Leg pain intensity, NRS (0-10); mean (SD) & $3.0(2.9)(n=2039)$ & $2.7(2.8)(n=744)$ & $3.0(2.9)(n=1980)$ & $2.9(2.9)(n=803)$ \\
\hline FABQ work subscale $(0-42)$ & $12.2(9.2)(n=|7| 5)$ & $13.7(10.0)(n=636)$ & $12.2(9.1)(n=1650)$ & $13.7(10.1)(n=701)$ \\
\hline Activity limitation, RMDQ (0-100) & $55.4(23.6)(n=2083)$ & $53.6(24.5)(n=765)$ & $55.0(23.5)(n=2023)$ & $54.8(24.8)(n=825)$ \\
\hline Use of medication, yes; $n(\%)$ & $104 \mid(51.0 \%)(n=2043)$ & $\mathrm{N} / \mathrm{A}$ & $924(51.4 \%)(n=1797)$ & $117(47.6 \%)(n=246)$ \\
\hline
\end{tabular}

Note: *All except medication are from Baseline I.

registry).$^{40}$ Merging of data from these and other national registries can be performed via Statistics Denmark for a minimal fee that covers their expenses for the handling of data.

A cohort study is designed to study the development and determinants of health and disease in a group of individuals who share a common experience or condition, and across subgroups within the cohort. ${ }^{41}$ Ideally, prognostic studies should begin at zero time, ie, at a welldefined time point that is common for all participants in the cohort, such as onset of disease (inception cohort), time of diagnosis, or beginning of treatment. ${ }^{42}$ Here we include participants at the beginning of treatment for a new episode of LBP for which there was no ongoing treatment or long-term management. This definition of zero time has inherent problems in LBP because for many people it is a chronic recurrent condition and previous care is very common. ${ }^{43,44}$ In addition, people with higher levels of chronicity and disability, ie, chronic exposure, are more likely to seek care, which may result in an over-representation in a cohort where care seeking is the event that triggers inclusion. ${ }^{41,45}$ We collected an extensive set of variables at baseline in order to be able to describe this cohort thoroughly, to study the influence of these variables on prognosis, and to adjust for factors that may confound relationships between baseline characteristics (exposures) and outcomes for the investigation of causal questions. To reduce the risk of prevalenceincidence bias, it will be possible to use information about participants' LBP history to define homogenous subsets within the cohort for specific research questions.

Danish chiropractic patients with LBP are not representative of Danish primary care patients with LBP. They have been shown to be younger, better educated, more often males, and have a better general health with fewer comorbidities when compared to people who seek care for LBP from Danish GPs. ${ }^{46}$ Also, patient profiles in the cohort cannot be assumed to be generalizable to chiropractic care globally. For example, a scoping review of people seeking chiropractic care for all reasons found a larger proportion of female patients (57\%) than in the ChiCo cohort $(41 \%){ }^{47}$ Whether this is due to differences across conditions (LBP versus all) or countries, or related to different attrition bias are unknown. Still, there is no reason to believe that relationships between patient factors investigated in the ChiCo cohort would generally not apply to other circumstances. This is to be considered for each question investigated. It is theoretically possible that only recruiting from larger clinics may have introduced some bias into the sample and patients in large clinics may more often be offered cross-disciplinary treatment, as the enrolled clinics more often had physiotherapist as part of the team as compared to Danish chiropractic clinics in general. We do not believe that recruiting in only one region of Denmark is likely to have biased the sample because chiropractic in Denmark is a very homogenous profession that is regulated and well integrated into the national healthcare system. Similarly, participant baseline demographics in the ChiCo cohort are comparable to those of the previous but smaller Danish cohort of chiropractic patients with LBP $(n=934)$ that was based on a national sample. ${ }^{46}$ The only exceptions were a slightly lower proportion of females in the ChiCo cohort ( $41 \%$ versus $45 \%$ ) and a higher proportion of participants without a qualifying education (16\% versus $7 \%)$.

In 2018, a group of international leading experts published a Call to Action in The Lancet that outlined a number of research priorities in order to address 

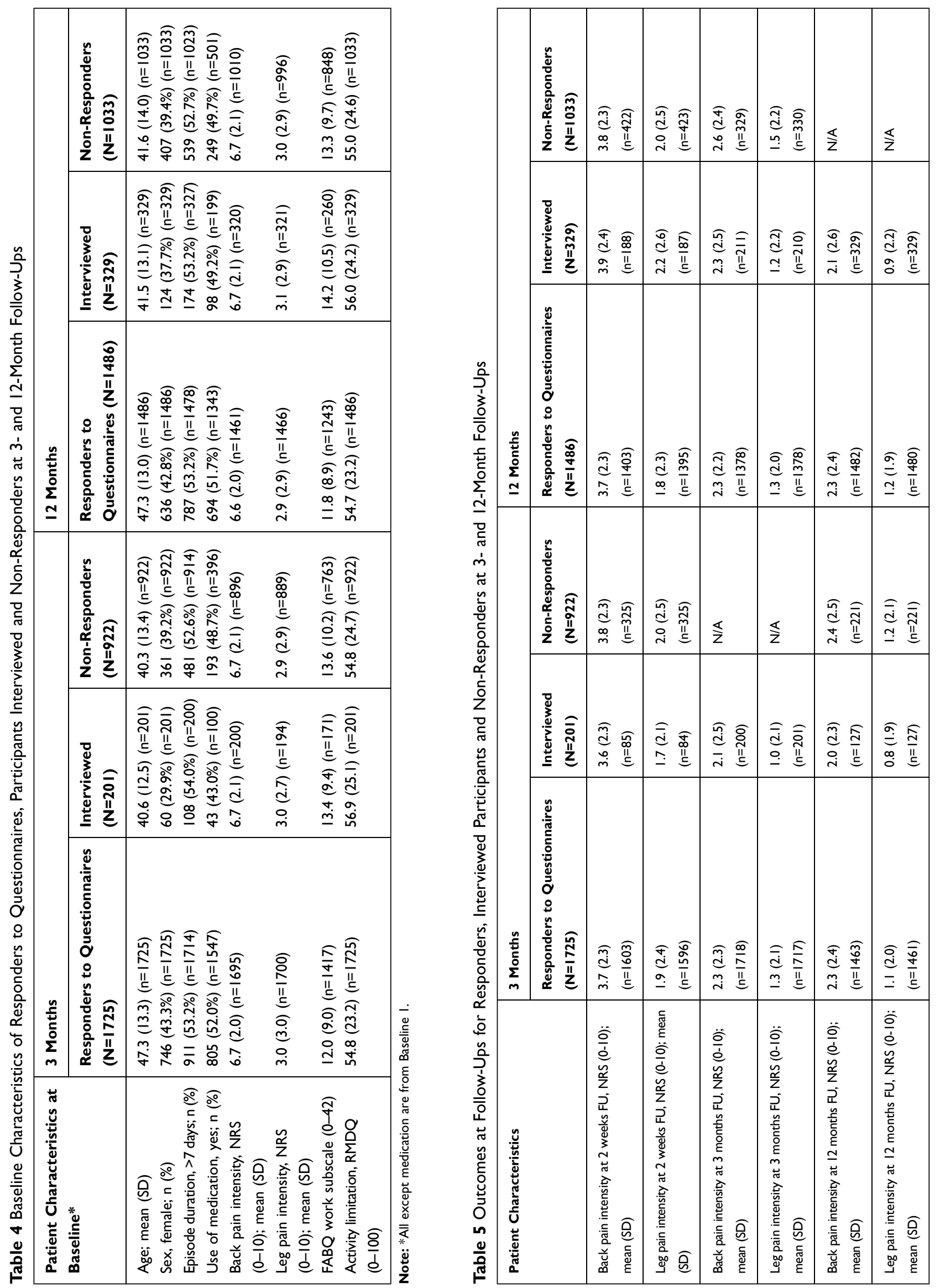
evidence gaps related to management of LBP in communities. ${ }^{48}$ Among those were research into prognosis of different LBP phenotypes, patient perceptions and behaviours, and social determinants of persistent LBP. Along with our pre-determined domains, these and other research questions can be addressed using this cohort alone or in combination with information in Danish registries.

\section{Conclusion}

The Chiropractic low back pain Cohort (ChiCo) is a large cohort of patients seeking care for LBP from primary care chiropractors in Denmark. Participants were followed for one year with good follow-up rates and a subset of participants had weekly follow-ups via SMS. A number of prespecified research areas of interest informed the choice of the measured variables, and information in the database can be linked at an individual level with the information-rich Danish population-based registries. We invite researchers interested in asking relevant questions from the ChiCo data to collaborate with us on projects based on the cohort.

\section{Data Sharing Statement}

Application forms to use the described data for research projects are available from the Nordic Institute of Chiropractic and Clinical Biomechanics (Orla Lund Nielsen).

\section{Ethics and Data Protection}

The Health Research Ethics Committee for Southern Denmark determined (S-20,162,000-109) that the project did not require ethical approval according to Danish regulations. ${ }^{49}$ Questionnaire surveys and medical database research projects only require notification to the research ethics committee system if the project involves human biological material. Storing and processing of personal data was registered with the Danish Data Protection Agency via the University of Southern Denmark's joint registration system (2015-57-0008), file no. 16/47,215. The legal basis of the processing of personal data was informed consent and complied with the European General Data Protection Regulation (GDPR EU 2016/679) Article 9, 2(a). Apart from stating their rights and describing the aim and setup of the cohort, the consent informed potential participants that their treatment would not be affected by participation and that the chiropractor would not have access to their questionnaire responses. Besides data collected directly from participants, consent also allowed researchers to acquire relevant data from Danish public registers, such as information on health-care utilization. Without patients explicitly giving study consent, it was technically impossible for them to enter any data.

\section{Acknowledgment}

The authors want to acknowledge participating patients, clinic staff, and clinicians for taking part in establishing the cohort. Thanks to research assistant Gitte Jakobsen for day-to-day contact to the clinics and to OPEN patient data Exploratory Network for access to REDCap and technical support.

\section{Author Contributions}

All authors made a significant contribution to the work reported, whether that is in the conception, study design, execution, acquisition of data, analysis and interpretation, or in all these areas; took part in drafting, revising or critically reviewing the article; gave final approval of the version to be published; have agreed on the journal to which the article has been submitted; and agree to be accountable for all aspects of the work.

\section{Funding}

Data collection and management of the database were funded by the Danish Foundation for Chiropractic Research and Post-graduate Education (file no. RTLN5550-16/621). The conduct of the study was financed by a grant from The Foundation for Chiropractic Research and Post-graduate Education.

\section{Disclosure}

AKs position at University of Southern Denmark is partially funded by the Danish Fund for Chiropractic Research and Postgraduate Education. TSJs position at NIKKB is funded by the Danish Fund for Chiropractic Research and Postgraduate Education. The authors report no other potential conflicts of interest for this work.

\section{References}

1. Hartvigsen J, Hancock MJ, Kongsted A, et al. What low back pain is and why we need to pay attention. Lancet. 2018;391 (10137):2356-2367. doi:10.1016/S0140-6736(18)30480-X

2. GBD 2017 Disease and Injury Incidence and Prevalence Collaborators. Global, regional, and national incidence, prevalence, and years lived with disability for 354 diseases and injuries for 195 countries and territories, 1990-2017: a systematic analysis for the Global Burden of Disease Study 2017. Lancet. 2018;392(10159):1789-1858.

3. Flachs EM, Erisken L, Koch MB, et al. Sygdomsbyrden I Danmark. Sygdomme. Copenhagen: Danish National Institute for Public Health; 2015. 
4. Foster NE, Anema JR, Cherkin D, et al. Prevention and treatment of low back pain: evidence, challenges, and promising directions. Lancet. 2018;391(10137):2368-2383. doi:10.1016/S0140-6736(18)30489-6

5. Institute of Medicine. Learning What Works: Infrastructure Required for Comparative Effectiveness Research: Workshop Summary. Washington, DC: The National Academies Press; 2011.

6. Sorensen LP, Stochkendahl MJ, Hartvigsen J, Nilsson NG. Chiropractic patients in Denmark 2002: an expanded description and comparison with 1999 survey. J Manipulative Physiol Ther. 2006;29(6):419-424. doi:10.1016/j.jmpt.2006.06.001

7. Lønnberg F. The management of back problems among the population. I. Contact patterns and therapeutic routines. Ugeskr Laeger. 1997;159(15):2207-2214.

8. Kongsted A, Kent P, Hestbaek L, Vach W. Patients with low back pain had distinct clinical course patterns that were typically neither complete recovery nor constant pain. A latent class analysis of longitudinal data. Spine J. 2015;15(5):885-894. doi:10.1016/j.spinee.2015.02.012

9. Kongsted A, Vach W, Axo M, Bech RN, Hestbaek L. Expectation of recovery from low back pain: a longitudinal cohort study investigating patient characteristics related to expectations and the association between expectations and 3-month outcome. Spine (Phila Pa 1976). 2014;39(1):81-90. doi:10.1097/BRS.0000000000000059

10. Kongsted A, Andersen CH, Hansen MM, Hestbaek L. Prediction of outcome in patients with low back pain - A prospective cohort study comparing clinicians' predictions with those of the Start Back Tool. Man Ther. 2016;21:120-127. doi:10.1016/j.math.2015.06.008

11. Morso L, Kongsted A, Hestbaek L, Kent P. The prognostic ability of the STarT Back Tool was affected by episode duration. Eur Spine J. 2016;25(3):936-944. doi:10.1007/s00586-015-3915-0

12. Kongsted A, Aambakk B, Bossen S, Hestbaek L. Brief screening questions for depression in chiropractic patients with low back pain: identification of potentially useful questions and test of their predictive capacity. Chiropr Man Therap. 2014;22(1):4. doi:10.1186/2045-709X-22-4

13. Myburgh C, Boyle E, Lauridsen HH, Hestbaek L, Kongsted A. What influences retrospective self-appraised recovery status among Danes with low-back problems? A comparative qualitative investigation. J Rehabil Med Suppl. 2015;47(8):741-747. doi:10.2340/16501977-1987

14. Hartvigsen L, Hestbaek L, Lebouef-Yde C, Vach W, Kongsted A. Leg pain location and neurological signs relate to outcomes in primary care patients with low back pain. BMC Musculoskelet Disord. 2017;18(1):133. doi:10.1186/s12891-017-1495-3

15. Hartvigsen L, Kongsted A, Vach W, Salmi LR, Hestbaek L. Does a diagnostic classification algorithm help to predict the course of low back pain? A study of Danish chiropractic patients with 1-year follow-up. J Orthop Sports Phys Ther. 2018;48(11):837-846. doi:10. 2519/jospt.2018.8083

16. Grøn S, Jensen RK, Jensen TS, Kongsted A. Back beliefs in patients with low back pain: a primary care cohort study. BMC Musculoskelet Disord. 2019;20(1):578. doi:10.1186/s12891-019-2925-1

17. Jakobsen G, Jensen TS, Kongsted A. Reassuring Patients with Low Back Pain in Primary Care Consultations: Does It Happen, and Does It Matter? A ChiCo Cohort Study. Submitted for publication; 2020.

18. Nielsen OL, Kongsted A, Christensen HW. The chiropractic profession in Denmark 2010-2014: a descriptive report. Chiropr Man Therap. 2015;23:27. doi:10.1186/s12998-015-0072-9

19. Danish Regions. Reimbursements chiropractic. Available from: https://www.regioner.dk/sundhed/praksissektoren/kiropraktik.

Accessed February 7, 2014.

20. Lauridsen HH, Hartvigsen J, Manniche C, Korsholm L, GrunnetNilsson N. Responsiveness and minimal clinically important difference for pain and disability instruments in low back pain patients. BMC Musculoskelet Disord. 2006;7:82. doi:10.1186/1471-2474-7-82

21. Linton SJ, Hallden K. Can we screen for problematic back pain? A screening questionnaire for predicting outcome in acute and subacute back pain. Clin J Pain. 1998;14(3):209-215. doi:10.1097/ 00002508-199809000-00007
22. Holt N, Pincus T. Developing and testing a measure of consultation-based reassurance for people with low back pain in primary care: a cross-sectional study. BMC Musculoskelet Disord. 2016;17(1):277.

23. Kongsted A, Christensen MR, Ingersen KK, Secher Jensen T. Feasibility of the consultation-based reassurance questionnaire in Danish chiropractic practice. Chiropr Man Therap. 2018;26:27. doi:10.1186/s12998-018-0197-8

24. Waddell G, Newton M, Henderson I, Somerville D, Main CJ. A Fear-Avoidance Beliefs Questionnaire (FABQ) and the role of fearavoidance beliefs in chronic low back pain and disability. Pain. 1993;52(2):157-168. doi:10.1016/0304-3959(93)90127-B

25. George SZ, Valencia C, Beneciuk JM. A psychometric investigation of fear-avoidance model measures in patients with chronic low back pain. J Orthop Sports Phys Ther. 2010;40(4):197-205. doi:10.2519/ jospt.2010.3298

26. Weermeijer JD, Meulders A. Clinimetrics: tampa scale for kinesiophobia. J Physiother. 2018;64(2):126. doi:10.1016/j.jphys.2018.01.001

27. Broadbent E, Wilkes C, Koschwanez H, Weinman J, Norton S, Petrie KJ. A systematic review and meta-analysis of the brief illness perception questionnaire. Psychol Health. 2015;30(11):1361-1385. doi:10.1080/08870446.2015.1070851

28. Jenkins HJ, Hancock MJ, Maher CG, French SD, Magnussen JS. Understanding patient beliefs regarding the use of imaging in the management of low back pain. Eur J Pain. 2016;20(4):573-580. doi:10.1002/ejp.764

29. Symonds TL, Burton AK, Tillotson KM, Main CJ. Do attitudes and beliefs influence work loss due to low back trouble? Occup Med (Lond). 1996;46(1):25-32. doi:10.1093/occmed/46.1.25

30. Albert HB, Jensen AM, Dahl D, Rasmussen MN. Criteria validation of the Roland morris questionnaire. A Danish translation of the international scale for the assessment of functional level in patients with low back pain and sciatica]. UgeskrLaeger. 2003;165(18):1875-1880.

31. Stroyer J, Essendrop M, Jensen LD, Warming S, Avlund K, Schibye B. Validity and reliability of self-assessed physical fitness using visual analogue scales. Percept Mot Skills. 2007;104 (2):519-533. doi:10.2466/pms.104.2.519-533

32. Hill JC, Dunn KM, Lewis M, et al. A primary care back pain screening tool: identifying patient subgroups for initial treatment. Arthritis Rheum. 2008;59(5):632-641. doi:10.1002/art.23563

33. Schneider M, Erhard R, Brach J, Tellin W, Imbarlina F, Delitto A. Spinal palpation for lumbar segmental mobility and pain provocation: an interexaminer reliability study. J Manipulative Physiol Ther. 2008;31(6):465-473. doi:10.1016/j.jmpt.2008.06.004

34. van der Windt DA, Simons E, Riphagen II, et al. Physical examination for lumbar radiculopathy due to disc herniation in patients with low-back pain. Cochrane Database Syst Rev. 2010;2: CD007431.

35. Suri P, Rainville J, Katz JN, et al. The accuracy of the physical examination for the diagnosis of midlumbar and low lumbar nerve root impingement. Spine (Phila Pa 1976). 2011;36(1):63-73. doi:10.1097/BRS.0b013e3181c953cc

36. Vleeming A, Albert HB, Ostgaard HC, Sturesson B, Stuge B. European guidelines for the diagnosis and treatment of pelvic girdle pain. Eur Spine J. 2008;17(6):794-819.

37. Medeiros FC, Costa LOP, Oliveira IS, Oshima RK, Costa LCM. The use of STarT BACK screening tool in emergency departments for patients with acute low back pain: a prospective inception cohort study. Eur Spine J. 2018;27(11):2823-2830. doi:10.1007/s00586018-5586-0

38. Andersen JS, Olivarius Nde F, Krasnik A. The Danish national health service register. Scand J Public Health. 2011;39(7 Suppl):34-37. doi:10.1177/1403494810394718

39. Lynge E, Sandegaard JL, Rebolj M. The Danish national patient register. Scand J Public Health. 2011;39(7 Suppl):30-33. doi: $10.1177 / 1403494811401482$ 
40. Statistics Denmark. The DREAM registry. Available from: https:// www.dst.dk/da/TilSalg/Forskningsservice/Data/Andre_Styrelser. Accessed May 22, 2020.

41. Rothman KJ, Lash TL, Greenland S. Modern Epidemiology. 3 ed. Philadelphia: Wolters Kluwer; 2008.

42. Fletcher RH, Fletcher SW. Clinical Epidemiology: The Essentials. 4th ed. Philadelphia: Lippincott Williams \& Wilkins; 2005.

43. da Silva T, Mills K, Brown BT, Herbert RD, Maher CG, Hancock MJ. Risk of recurrence of low back pain: a systematic review. J Orthop Sports Phys Ther. 2017;47(5):305-313. doi:10. 2519/jospt.2017.7415

44. da Silva T, Mills K, Kongsted A, Maher C, Hancock M. What is the personal impact of recurrences of low back pain? Subanalysis of an Inception Cohort Study. J Orthop Sports Phys Ther. 2020;1-18.

45. Ferreira ML, Machado G, Latimer J, Maher C, Ferreira PH, Smeets RJ. Factors defining care-seeking in low back pain-a metaanalysis of population based surveys. Eur J Pain. 2010;14(7):747. e741-747. doi:10.1016/j.ejpain.2009.11.005
46. Hestbaek L, Munck A, Hartvigsen L, Jarbol DE, Sondergaard J, Kongsted A. Low back pain in primary care: a description of 1250 patients with low back pain in danish general and chiropractic practice. Int J Family Med. 2014;2014:106102. doi:10.1155/2014/ 106102

47. Beliveau PJH, Wong JJ, Sutton DA, et al. The chiropractic profession: a scoping review of utilization rates, reasons for seeking care, patient profiles, and care provided. Chiropr Man Therap. 2017;25 (1):35.

48. Buchbinder R, van Tulder M, Oberg B, et al. Low back pain: a call for action. Lancet. 2018;391(10137):2384-2388. doi:10.1016/S01406736(18)30488-4

49. The Danish National Committee on Health Research Ethics. Act on research ethics review of health research projects. 2020 [Updated November 13, 2018]. Available from: https://en.nvk.dk/. Accessed May 22, 2020.

\section{Publish your work in this journal}

Clinical Epidemiology is an international, peer-reviewed, open access, online journal focusing on disease and drug epidemiology, identification of risk factors and screening procedures to develop optimal preventative initiatives and programs. Specific topics include: diagnosis, prognosis, treatment, screening, prevention, risk factor modification,

Submit your manuscript here: https://www.dovepress.com/clinical-epidemiology-journal systematic reviews, risk \& safety of medical interventions, epidemiology \& biostatistical methods, and evaluation of guidelines, translational medicine, health policies \& economic evaluations. The manuscript management system is completely online and includes a very quick and fair peer-review system, which is all easy to use. 